\title{
Internal and External Demands in Basketball Referees during the U-16 European Women's Championship
}

\author{
David García-Santos ${ }^{1, *(1)}$, José Pino-Ortega ${ }^{2, *}$, Javier García-Rubio ${ }^{1}\left[\right.$, Alejandro Vaquera ${ }^{3}$ (i) \\ and Sergio J. Ibáñez $1, * \mathbb{D}$ \\ 1 Faculty of Sports Science, University of Extremadura. Optimization of Training and Sport Performance \\ Research Group, 10071 Cáceres, Spain; jagaru@unex.es \\ 2 Faculty of Sports Science, University of Murcia, 30730 San Javier, Spain \\ 3 Faculty of Sports Science, University of Leon, 24001 León, Spain; avaqj@unileon.es \\ * Correspondence: dgarcianu@alumnos.unex.es (D.G.-S); pepepinoortega@gmail.com (J.P.-O.); \\ sibanez@unex.es (S.J.I.); Tel.: +34-927-25-74-60
}

Received: 9 August 2019; Accepted: 11 September 2019; Published: 14 September 2019

\begin{abstract}
Background: The use of advanced technology to study the energy demands of sport participants during actual sport competition is an important current research direction. The purpose of this study was to identify the physiological, internal, and external demands placed on basketball referees using ultra-wideband (UWB) technology, in relation to the period of the game. (2) Methods: The sample was comprised of nine international referees, and the data collection took place during the Women's EuroBasket Sub-16 championship. Internal and external load were assessed through the inertial device WIMU PRO ${ }^{\mathrm{TM}}$, using UWB technology in order to quantify the effort exerted by each referee. The internal load was examined in relation to each individual's heart rate (HR). The external load included the kinematic variables accelerations (Acc), decelerations (Dec), Acc/min, Dec/min, distance covered, steps, maximum speed (Vmax), average speed (Vavg), and speed zones, as well as the neuromuscular variables impacts (Imp), PlayerLoad ${ }^{T M}\left(P L^{T M}\right), P L^{T M} / \mathrm{min}$, Metabolic Power (PMet), and PMet/min. (3) Results: The results exposed that referees work around $62 \%$ HRmax and spend more than $80 \%$ of the match at intensities between $0-12 \mathrm{~km} / \mathrm{h}$. The first period was the period in which the greatest work demand was experienced in relation to these neuromuscular outcomes (11.92 PL; 3.61 Met; 277 Impacts). The results revealed a diminishment of internal and external demands on the referees over the course of the game. (4) Conclusions: The results highlight the importance of monitoring and quantifying the workload of basketball officials, because doing so would allow for the establishment of individualized performance profiles that could be designed with the purpose of benefiting referee performance during games. The use of inertial devices allows for the objective quantification of referee workload under competitive circumstances.
\end{abstract}

Keywords: basketball referee; external training load; internal training load; competition

\section{Introduction}

Basketball is a sport that has been in continuous evolution since its beginnings due to changes in the rules of the game that have been designed to create a more dynamic and attractive game for the spectator [1,2]. These changes have caused an exponential increase in the physical demands placed on the players and referees during competition [2]. Research that has been conducted to examine the workload demands of basketball participants has focused principally on players' energy demands [3]; only infrequent studies have addressed the referees' workloads. As such, it is necessary to better understand the demands of the game that the referees experience [4], as doing so should benefit referee physical preparation and self-efficacy [5]. This knowledge would also be vital for the development of 
individualized physical training programs [6], and to better understand the decision-making process as it occurs during competitive circumstances [7].

The physical demands of refereeing the sport of basketball include internal demands, most commonly determined through heart rate (HR) values, and external demands [8]. Various studies have assessed heart rate in referees of team sports, such as women's basketball (60-70\% HRmax) [9]; men's basketball ( 80\% HRmáx) [10-12]; football (>80\% HR) [13,14]; futsal ( 80\% HRmax) $[15,16]$, and handball (60-70\% HRmax) [17]. Other research studies have utilized additional work parameters focused instead on the kinematic and neuromuscular workload demands, such as distance covered, speed, accelerations, metabolic energy, or PlayerLoad ${ }^{\text {TM }}$ [18-22]. These parameters provide additional objective data relative to the physical demands placed on referees during competitive circumstances: individual fitness level, type of competition (local, national, or international), numbers of referees (two or three), gender of teams (men or women), and characteristics of the game (close game, game style, etc.) [23]. In addition, these variables of internal and external load can be associated with the levels of stress and fatigue of referees during their intervention, which may affect referees' decision making $[24,25]$. In order to develop a suitable decision-making process, it will be necessary to have an adequate fitness condition profile to be situated in the right place that enables accurately judging the actions that occur during the competition.

Included among the measurement methods that allow for the assessment of kinematic variables (distance covered, speed, range of speed) are pedometers [22], video-based tracking (VBT) [1,20], and global positioning systems such as the Global Navigation Satellite System (GNSS), which requires a tracking device (HDOP) and a quality signal (GDOP). The VBT system is a non-invasive system, given that the players and the referees do not need to apply any sort of electronic tracking device. Nonetheless, the use of this system is limited to spaces where video cameras are installed, and thus presents an indirect albeit reliable means of measurement. The GNSS technology requires that players wear a device that enables the tracking of the individual's positioning through a satellite [26], and is thus limited to assessing referee outcomes in sports that are played outdoors, such as football $[19,27,28]$ or rugby [21]. Nonetheless, with the development of the ultra-wideband (UWB) technology, it is possible to identify the positioning of athletes and referees in indoor sports with greater confidence through the GNSS technology [29-31]. Installation of the system is quite simple, and only requires the placement of six antennas to obtain radio frequencies that determine the nearly exact positioning of each athlete or official with only the slightest errors [28]. The use of these devices allowed the quantification of workload demands and performance in an objective manner, and enables the possibility of working more precisely with those behavioral outcomes that can be of greatest benefit to each referee [10].

Use of the UWB devices has been relatively recent [30,32], and their use has typically been limited to the examination of the validity and reliability of these instruments in experimental situations $[29,31]$. The present study had the purpose of determining the internal and external workload demands placed on basketball referees during a recent international competition, to subsequently establish training programs according to the needs of each referee. In addition, the study was focused on understanding variation in workload demand across periods of play. The UWB technology was employed to address these research interests.

\section{Materials and Methods}

\subsection{Design}

The present study utilized a cross-sectional design with existing groups [33] to better understand the internal and external demands placed on referees at the international level. The study took place during the Women's EuroBasket U-16 championship that was held in Gibraltar in 2017. 


\subsection{Participants}

The sample was comprised of nine (six male and three female) international-level basketball referees. The characteristics of the sample are provided in Table 1 . These referees officiated 15 games during the championship. The participants were appointed by the International Basketball Federation (FIBA). Therefore, it was not possible to conduct fitness tests before the championship.

Table 1. Anthropometric and demographic data of referees $(\mathrm{N}=9)$.

\begin{tabular}{ccccccc}
\hline & \multicolumn{3}{c}{ Male (6) } & \multicolumn{3}{c}{ Female (3) } \\
\hline & Mean & Minimum & Maximum & Mean & Minimum & Maximum \\
\hline Age (Yrs.) & 44 & 37 & 49 & 39 & 34 & 44 \\
Experience (Yrs.) & 25 & 20 & 32 & 15 & 10 & 21 \\
Height (m) & 1.83 & 1.78 & 1.96 & 1.74 & 1.70 & 1.80 \\
Body Mass (kg) & 78.48 & 67.3 & 92.5 & 71.13 & 61.2 & 86.9 \\
Body Fat (\%) & 13.55 & 9.5 & 16.3 & 23.87 & 19.9 & 29.2 \\
Muscle Mass (\%) & 64.27 & 55.7 & 73.6 & 50.80 & 46.5 & 57.9 \\
Bone Mass (\%) & 3.33 & 2.9 & 3.8 & 2.73 & 2.5 & 3.1 \\
BMI & 23.17 & 20.4 & 25.1 & 23.27 & 20.4 & 26.8 \\
DCI (kcal) & 4079 & 3530 & 4748 & 2865 & 2619 & 3284 \\
Metabolic Age (Yrs.) & 29 & 22 & 34 & 27 & 19 & 37 \\
Body Water (\%) & 62.28 & 59.5 & 65.5 & 55.67 & 51.6 & 58.4 \\
Visceral Fat (\%) & 5 & 4 & 7 & 3 & 1 & 5 \\
\hline
\end{tabular}

Note: $\mathrm{BMI}=$ Body Mass Index $;$ DCI = Daily Calorie Intake.

\subsection{Ethics}

Each of the referees was informed of the experimental protocol and the possible benefits of their participation before providing their consent to participate in the study. Each of the participants provided a signed informed consent prior to involvement. Each of the procedures included in the study were approved in advance by the Ethical Committee of the University of Extremadura $\left(\mathrm{n}^{\circ} 17 / 2017\right)$, and in accordance with the Helsinki Declaration (2013). The FIBA also authorized all the protocols that were utilized.

\subsection{Variables}

The period of play served as the independent variable in this investigation. At this level of play, the game consists of four 10-minute periods (or quarters) of play. The dependent variables were each of the internal (physiological) demands and external (kinematic and neuromuscular) demands that were assessed in the study. Thus, the study was designed to determine the workload demands placed on basketball referees and to identify any differences that may have emerged in these workload demands over the four quarters of the game.

\subsection{Internal Load}

Heart rate was defined as the percentage of maximum heart rate $(\% \mathrm{HRmax})$ that was experienced by each referee in each of the four periods of the game. Six workload categories, or heart rate (HR) zones, were utilized that corresponded with those proposed by Vaquera et al., [12]: $H R_{1}(50-60 \%$ HRmax); HR 2 (60-70\% HRmax); HR 3 (70-80\% HRmax); HR 4 (80-90\% HRmax); HR 5 (90-95\% HRmax); $H R_{6}$ (>95\% HRmax). Each referee's HRmax was established by determining the maximum HR value that they attained over the course of the game, and the heart rate zones reflected the percentage with 
each individual's maximum heart rate. The HRmax for each referee was calculated in accordance of the formula proposed by Whaley, Kaminsky, Dwyer, Getchell, and Norton [34]:

$$
\begin{gathered}
\text { Men } \\
\text { HRmax }(\text { bpm })=203.9-[0.812 * \text { Age }]+[0.276 * \text { HRbasal }]-[0.084 * \text { Body Mass }] \\
\text { Women } \\
\text { HRmax }(\text { bpm })=204.8-[0.718 * \text { Age }]+[0.162 * \text { HRbasal }]-[0.105 * \text { Body Mass }]
\end{gathered}
$$

\subsection{External Load}

The external variables employed in this study were: accelerations (Acc); decelerations (Dec); distance covered (Dis); steps (St); maximum speed (Vmax); average speed (Vavg); impacts (n), PlayerLoad $^{\mathrm{TM}}$ (Pl) and Metabolic Power (Pmet).

Firstly, the number of accelerations (Acc) and decelerations (Dec) per game and period were determined, as well as Acc and Dec per minute in each period. The value established for its calculation was greater than 1 or $-1 \mathrm{~m} / \mathrm{s}^{2}$.

The variables of distance covered (meters) and steps ( $n$ ) were measured through the inertial device, taking its values by periods and throughout the game.

The maximum speed (Vmax), the average speed (Vavg), and different speed zones were determined for the speed variable. The ranges of speed zones were: $V_{1}=0-6 \mathrm{~km} / \mathrm{h}$ (walking); $V_{2}=6-12 \mathrm{~km} / \mathrm{h}$ (jogging); $\mathrm{V}_{3}=12-18 \mathrm{~km} / \mathrm{h}$ (running); and $\mathrm{V}_{4}=18-21 \mathrm{~km} / \mathrm{h}$ (sprinting). These ranges of speed were established according to criteria developed by Gómez-Carmona and Pino-Ortega, [19] and based on the characteristic demands of basketball officiating.

Impacts were measured by G-forces that the referees experienced during different game actions. The calculation of this variable was achieved by summing the vector of G-forces that the referee experienced across three axes $(x, y$, and $z)$. The impact value was established when the $G$-forces of the movement exceeded 5 Gs [35].

The variable of PlayerLoad $(P L)$ was defined as the sum of the acceleration vectors as assessed through the inertial device employed (WIMU PRO ${ }^{\mathrm{TM}}$ ) and in each of the three axes (vertical, anterior-posterior, and lateral). The PlayerLoad variable has demonstrated strong reliability and validity indices [36,37] to assess the neuromuscular load of each referee [38]. The corresponding value was calculated through the following equation, where $Z$ represents acceleration from the anterior to posterior direction, $X$ refers to acceleration in the medial-lateral direction, and $Y$ refers to vertical acceleration. Time is represented by $t$ and $n$ refers to number.

$$
\text { PlayerLoad }_{t=n} \sum_{t=0}^{t=n} \sqrt{\frac{\left(Z_{t=i+1}-Z_{t=i}\right)^{2}+\left(X_{t=i+1}-X_{t=i}\right)^{2}+\left(Y_{t=i+1}-Y_{t=i}\right)^{2}}{100}}
$$

The variable of Metabolic Power (PMet) was obtained by multiplying the velocity $(V)$ by the energy cost of the activity $(E C)$, as represented by the rate of acceleration [39]. The value was obtained through the following formula:

$$
P M e t=E C \cdot V
$$

\subsection{Materials}

A variety of instruments were used in the study. The Tanita Model BC-601 (TANITA, Tokyo, Japan) scale was used for the measurement of body composition values. A portable tallimeter device (SECA, Hamburg, Germany) was used to assess the height of each referee, and each individual was measured without shoes. To determine internal demand (\%HR), the GARMIN ${ }^{\circledR}$ Cardiac Frequency bands were used. This instrument consists of a belt with two electrodes and a small electronic device that receives the signals from the electrodes; then, the received data is synchronized with the inertial 
device WIMU PRO ${ }^{\mathrm{TM}}$ (Realtrack System, Almería, Spain) through wireless $\mathrm{ANT}^{+}$technology [40]. The WIMU PRO ${ }^{\mathrm{TM}}$ (wireless inertial unit movement) was used to monitor the external and internal loads. The device was integrated through different sensors (global position system, or GPS), three accelerometers, a gyroscope and an ultra-wideband (UWB) chip. The frequency for the chip's signal was $18 \mathrm{~Hz}$. The UWB-based system has been valid and reliable for analysis in outdoor and indoor sports [41]. In addition, a six-radiofrequency antenna system was used, which was located near the floor. This system allowed the location of each referee to be known at each moment. The calibration of these antennas was made according to the dimensions of the court, as reflected in Figure 1. Then, the data that were obtained through the devices were analyzed through specific software S-PRO ${ }^{\mathrm{TM}}$ (RealTrack Systems, Almería, Spain). All appropriate permissions have been obtained for WIMU PRO systems and S-PRO software for research purposes, as well as mention in subsequent publications.
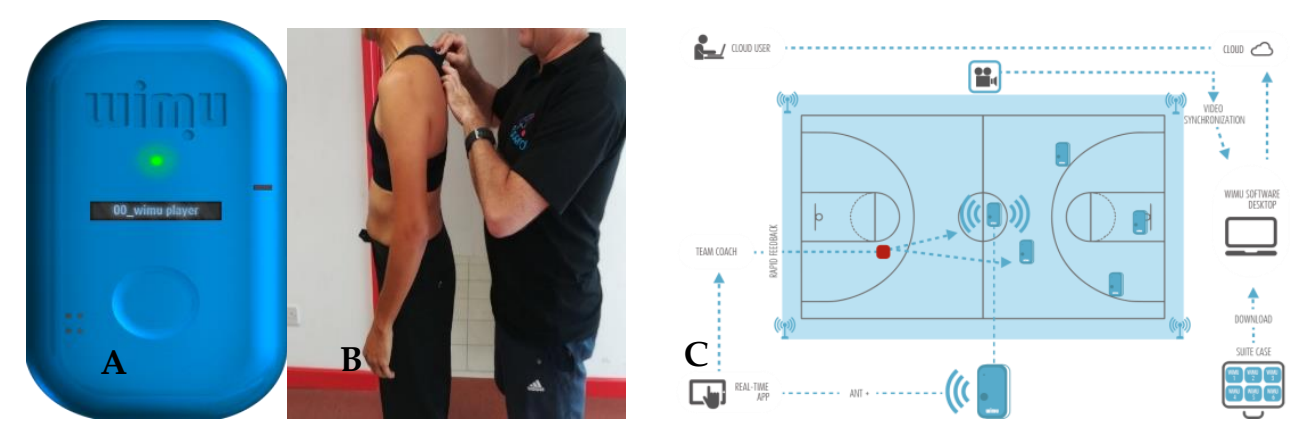

Figure 1. A: WIMU PRO ${ }^{\mathrm{TM}}$ (wireless inertial unit movement) ready to use; B: Introduction of the WIMU PRO device on a specific harness; C: The antenna system's placement (All appropriate permissions have been obtained from the copyright holders as well as written informed consent from the depicted individuals for the publication of this image).

\subsection{Statistical analysis}

The first step in the statistical analysis involved a test of parametric assumptions. These tests were conducted to examine homoscedasticity, the presence of outliers, and the normality assumption [42]. The results supported the suitability of the data in meeting the parametric assumptions and subsequent parametric analysis. A descriptive analysis of the data was conducted, and calculations of each variable's mean value, standard deviation, associated confidence intervals, and minimum and maximum values were conducted. Finally, a one-factor analysis of variance (ANOVA) was conducted to determine if differences in referee workload levels varied by game period. In this analysis, effect size $(f)$ and power $(\phi)$ were also calculated. For the interpretation of these findings, effect sizes were established as follows: $f$ $=0.10$ small $;=0.25$ medium; and $f=0.40$ large [43]. Bonferroni post-hoc analysis was used to identify any significant differences in workload outcomes across periods. The statistical analysis was completed through statistical package SPSS (SPSS Inc., Chicago IL, EEUU) version 21. Significance criteria were established throughout at $p<0.05$.

\section{Results}

Descriptive and inferential data of the internal load are presented in Table 2. The heart rate data indicates that these referees worked above $62 \%$ HRmax with a HRavg of 124 beats per minute and spent $83 \%$ of each period between $50-80 \%$ HRmax. The analysis was conducted through a single-factor ANOVA with a subsequent post-hoc Bonferroni analysis revealing significant differences between the second and third periods in \%HRmax $(p \leq 0.05)$ and HRavg $(p \leq 0.05)$. Significant differences also emerged between the first and third periods in $70-80 \%$ HRmax $(p \leq 0.05)$. 
Table 2. Descriptive and Inferential Results of the Internal Load Variables.

\begin{tabular}{|c|c|c|c|c|c|c|c|c|c|c|c|c|c|c|}
\hline \multirow{2}{*}{ Variables } & & \multirow{2}{*}{ Periods } & \multirow{2}{*}{ Mean } & \multirow{2}{*}{ SD } & \multicolumn{2}{|c|}{$95 \%$ IC } & \multirow{2}{*}{ Min } & \multirow{2}{*}{ Max } & \multirow{2}{*}{$F$} & \multirow{2}{*}{ Sig. } & \multirow{2}{*}{$f$} & \multirow{2}{*}{$\phi$} & \multirow{2}{*}{$p$} & \multirow{2}{*}{$\mathrm{DbP}$} \\
\hline & & & & & L & $\mathbf{U}$ & & & & & & & & \\
\hline \multicolumn{15}{|c|}{ Internal Load Variables } \\
\hline \multirow{6}{*}{ \%HRMax } & & 1 & 63 & 8 & 61 & 65 & 42 & 77 & \multirow{5}{*}{3.155} & \multirow{5}{*}{0.026} & \multirow{5}{*}{0.982} & \multirow{5}{*}{1.000} & \multirow{5}{*}{ * } & \multirow{5}{*}{$\pi$} \\
\hline & & 2 & 64 & 8 & 61 & 66 & 47 & 82 & & & & & & \\
\hline & & 3 & 59 & 9 & 57 & 62 & 36 & 85 & & & & & & \\
\hline & & 4 & 60 & 9 & 57 & 63 & 36 & 86 & & & & & & \\
\hline & & TG & 62 & 7 & 60 & 64 & 47 & 78 & & & & & & \\
\hline & & 2 & 128 & 17 & 123 & 133 & 93 & 164 & & & & & & \\
\hline \multirow[t]{15}{*}{ HRavg (bpm) } & & 3 & 119 & 18 & 113 & 124 & 71 & 169 & 3.155 & 0.026 & 0.982 & 1.000 & * & $\pi$ \\
\hline & & 4 & 120 & 18 & 114 & 125 & 72 & 172 & & & & & & \\
\hline & & TG & 124 & 14 & 119 & 128 & 93 & 156 & & & & & & \\
\hline & \multirow{4}{*}{$50-60 \%$} & 1 & 25.52 & 21.00 & 19.14 & 31.91 & 0.00 & 73.22 & \multirow{4}{*}{2.505} & \multirow{4}{*}{0.061} & & & & \\
\hline & & 2 & 26.83 & 21.64 & 20.25 & 33.41 & 0.00 & 69.67 & & & & & & \\
\hline & & 3 & 35.51 & 21.09 & 29.17 & 41.84 & 0.00 & 65.12 & & & 0.669 & 1.000 & & \\
\hline & & 4 & 34.61 & 23.31 & 27.61 & 41.62 & 0.00 & 69.73 & & & & & & \\
\hline & & 2 & 38.74 & 23.06 & 31.72 & 45.75 & 0.00 & 81.87 & & & & & & \\
\hline & $60-70 \%$ & 3 & 33.38 & 20.73 & 27.15 & 39.60 & 0.00 & 74.45 & 0.814 & 0.488 & 0.741 & 1.000 & & \\
\hline & & 4 & 36.32 & 23.25 & 29.34 & 43.31 & 0.00 & 88.24 & & & & & & \\
\hline & & TG & 36.88 & 19.39 & 31.05 & 42.70 & 0.00 & 72.41 & & & & & & \\
\hline & & 1 & 20.13 & 22.54 & 13.27 & 26.98 & 0.00 & 76.90 & & & & & & \\
\hline & & 2 & 18.68 & 20.87 & 12.34 & 25.03 & 0.00 & 71.83 & & & & & & \\
\hline & $70-80 \%$ & 3 & 10.53 & 17.21 & 5.36 & 15.70 & 0.00 & 70.30 & 2.799 & 0.042 & 0.379 & 1.000 & $*$ & $\beta$ \\
\hline & & 4 & 11.37 & 17.59 & 6.08 & 16.65 & 0.00 & 84.37 & & & & & & \\
\hline Zones HRMax (\% time per zones) & & TG & 15.04 & 17.89 & 9.67 & 20.42 & 0.00 & 75.35 & & & & & & \\
\hline & & 1 & 2.91 & 8.42 & 0.35 & 5.47 & 0.00 & 51.50 & & & & & & \\
\hline & & 2 & 4.29 & 11.06 & 0.92 & 7.65 & 0.00 & 51.44 & & & & & & \\
\hline & $80-90 \%$ & 3 & 1.70 & 7.08 & -0.42 & 3.83 & 0.00 & 42.79 & 0.928 & 0.428 & 0.091 & 0.986 & & \\
\hline & & 4 & 1.71 & 6.78 & -0.33 & 3.75 & 0.00 & 36.07 & & & & & & \\
\hline & & TG & 2.65 & 6.09 & 0.82 & 4.48 & 0.00 & 27.50 & & & & & & \\
\hline
\end{tabular}


Table 2. Cont.

\begin{tabular}{|c|c|c|c|c|c|c|c|c|c|c|c|c|c|c|}
\hline \multirow{2}{*}{ Variables } & & \multirow{2}{*}{ Periods } & \multirow{2}{*}{ Mean } & \multirow{2}{*}{ SD } & \multicolumn{2}{|c|}{$95 \%$ IC } & \multirow{2}{*}{ Min } & \multirow{2}{*}{ Max } & \multirow{2}{*}{$F$} & \multirow{2}{*}{ Sig. } & \multirow{2}{*}{$f$} & \multirow{2}{*}{$\phi$} & \multirow{2}{*}{$p$} & \multirow{2}{*}{$\mathrm{DbP}$} \\
\hline & & & & & L & $\mathbf{U}$ & & & & & & & & \\
\hline & \multirow{5}{*}{$90-95 \%$} & 1 & 0.28 & 1.88 & -0.29 & 0.86 & 0.00 & 12.48 & \multirow{5}{*}{0.325} & \multirow{5}{*}{0.807} & \multirow{5}{*}{0.033} & \multirow{5}{*}{0.673} & & \\
\hline & & 2 & 0.70 & 2.68 & -0.11 & 1.52 & 0.00 & 12.64 & & & & & & \\
\hline & & 3 & 0.35 & 2.32 & -0.35 & 1.04 & 0.00 & 15.59 & & & & & & \\
\hline & & 4 & 0.32 & 2.12 & -0.32 & 0.95 & 0.00 & 14.23 & & & & & & \\
\hline & & TG & 0.40 & 1.49 & -0.05 & 0.85 & 0.00 & 7.44 & & & & & & \\
\hline & \multirow{5}{*}{$>95 \%$} & 1 & 0.09 & 0.59 & -0.09 & 0.27 & 0.00 & 3.93 & \multirow{5}{*}{0.479} & \multirow{5}{*}{0.697} & \multirow{5}{*}{0.015} & \multirow{5}{*}{0.364} & & \\
\hline & & 2 & 0.19 & 1.26 & -0.19 & 0.57 & 0.00 & 8.37 & & & & & & \\
\hline & & 3 & 0.00 & 0.00 & 0.00 & 0.00 & 0.00 & 0.00 & & & & & & \\
\hline & & 4 & 0.08 & 0.57 & -0.09 & 0.26 & 0.00 & 3.81 & & & & & & \\
\hline & & TG & 0.09 & 0.36 & -0.02 & 0.20 & 0.00 & 2.04 & & & & & & \\
\hline
\end{tabular}

Note: $\mathrm{SD}=$ Standard Deviation; IC = Interval confidence; $\mathrm{L}=$ Low; $\mathrm{U}=$ Upper; Min = Minimum; Max = Maximum; DbP = Differences between periods; HRmax = Heart Rate Maximum;

HRavg = Heart Rate Average; $* *=p<0.01 ;^{*}=p<0.05 ; \mathrm{f}=$ Effect Size; $\phi=$ Power; $\beta=$ Differences between first and third periods; $\pi=$ Differences between second and third periods. 
Tables 3 and 4 provide the results of the study in relation to the external variables. It can be noted that the referees engaged in roughly 270 accelerations and 128 decelerations per period. They covered an average of $4330 \mathrm{~m}$ per game, reaching a peak velocity of $18.91 \mathrm{~km} / \mathrm{h}$ with an average velocity of $4.87 \mathrm{~km} / \mathrm{h}$ while taking 2616 steps per game. During $80.43 \%$ of game time, the referees worked at a velocity between $0-12 \mathrm{~km} / \mathrm{h}$. The referees received 1025 impacts on average per game, which reflects a workload of 44.13 PL and an energy cost of 15.60 Mets. The first period was the period in which the greatest work demand was experienced in relation to these neuromuscular outcomes (11.92 PL; 3.61 Met; 277 Impacts). The same tables provide the results of the analysis that compared differences across periods. In relation to this, a single-factor ANOVA with a subsequent post-hoc Bonferroni analysis revealed that significant differences existed between the first and third periods in average speed $(p \leq 0.05)$ and amount of time spent in the speed zone $V_{3}(p \leq 0.01)$. Significant differences also emerged between the first and fourth quarter in average speed ( $p \leq 0.01)$; steps taken ( $p \leq 0.05)$; PlayerLoad ( $p$ $\leq 0.01)$; PlayerLoad/min ( $p \leq 0.05)$; Metabolic Power ( $p \leq 0.01)$; Metabolic Power/min ( $p \leq 0.05)$; distance covered ( $p \leq 0.01)$; distance covered/min $(p \leq 0.05)$; speed zones $V_{3}(p \leq 0.01)$; and $V_{4}(p \leq 0.01)$. Finally, significant differences were found in speed zone $V_{3}$ between the first and third periods ( $p \leq 0.05$ ), as well as between the second and fourth periods in the same speed range $(p \leq 0.05)$. The effect sizes were large for each of these differences, and were as follows: $\operatorname{Vavg}(f=0.997)$; Steps $(f=0.961) ; P L(f=0.973)$; PL/min $(f=0.973) ;$ PMet $(f=0.969) ;$ PMet $/$ min $(f=0.976) ;$ Distance $(f=0.982) ;$ Distance/min $(f=0.986) ; V_{3}$ $(f=0.925)$; and $V_{4}(f=0.614)$. 
Table 3. Descriptive and Inferential Results of the External Load Variables (Kinematic Variables).

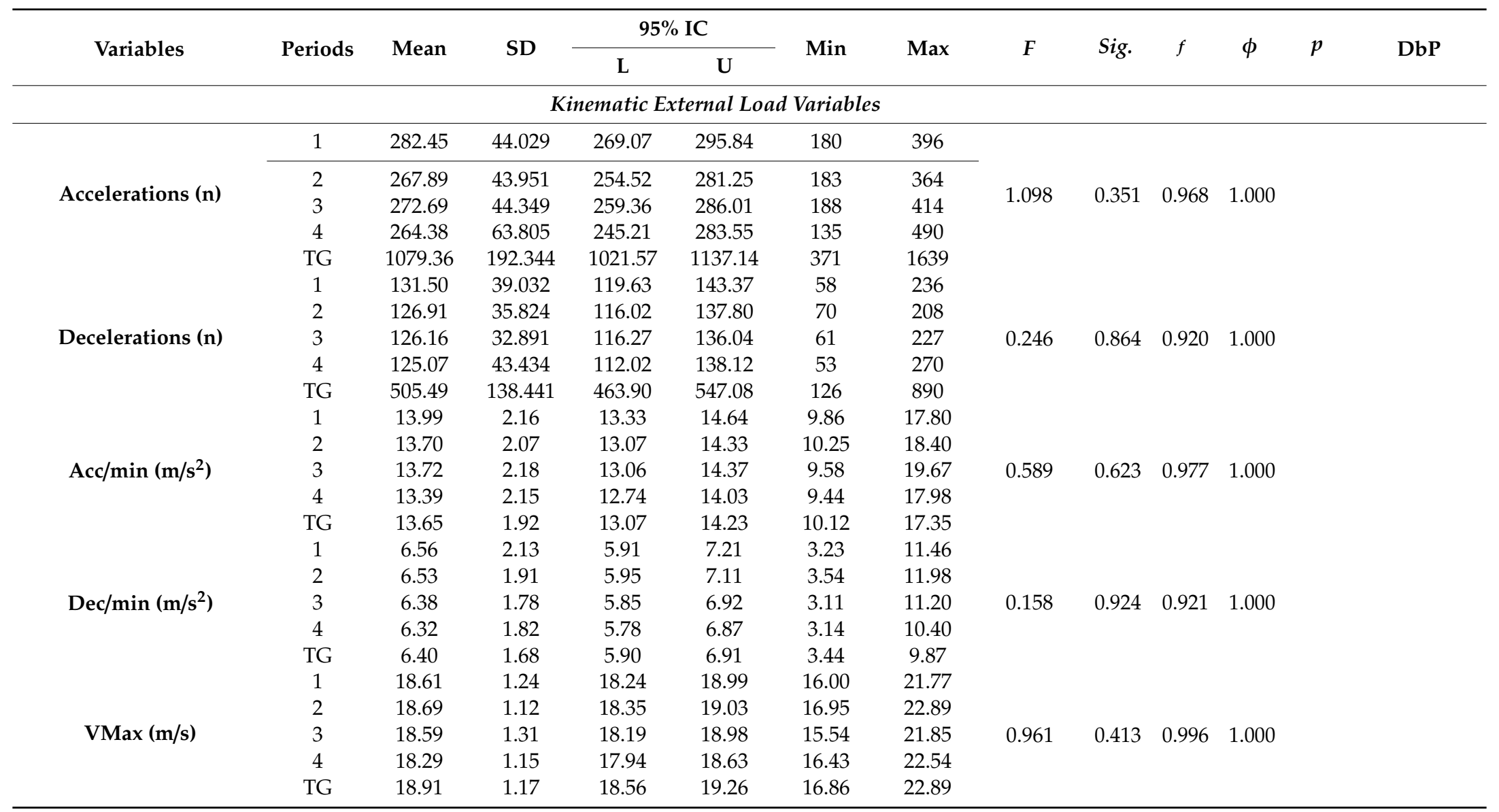


Table 3. Cont.

\begin{tabular}{|c|c|c|c|c|c|c|c|c|c|c|c|c|c|}
\hline \multirow{2}{*}{ Variables } & \multirow{2}{*}{ Periods } & \multirow{2}{*}{ Mean } & \multirow{2}{*}{ SD } & \multicolumn{2}{|c|}{$95 \%$ IC } & \multirow{2}{*}{ Min } & \multirow{2}{*}{$\operatorname{Max}$} & \multirow{2}{*}{$F$} & \multirow{2}{*}{ Sig. } & \multirow{2}{*}{$f$} & \multirow{2}{*}{$\phi$} & \multirow{2}{*}{$p$} & \multirow{2}{*}{$\mathrm{DbP}$} \\
\hline & & & & L & $\mathbf{U}$ & & & & & & & & \\
\hline \multirow{5}{*}{$\operatorname{Vavg}(\mathrm{m} / \mathrm{s})$} & 1 & 4.99 & 0.23 & 4.92 & 5.06 & 4.52 & 5.57 & \multirow{5}{*}{4.843} & \multirow{5}{*}{0.003} & \multirow{5}{*}{0.997} & \multirow{5}{*}{1.000} & \multirow{5}{*}{$* *$} & \multirow{5}{*}{$\gamma \beta$} \\
\hline & 2 & 4.89 & 0.29 & 4.80 & 4.97 & 4.32 & 5.77 & & & & & & \\
\hline & 3 & 4.83 & 0.27 & 4.75 & 4.91 & 4.27 & 5.40 & & & & & & \\
\hline & 4 & 4.78 & 0.31 & 4.69 & 4.87 & 4.12 & 5.36 & & & & & & \\
\hline & TG & 4.87 & 0.21 & 4.80 & 4.93 & 4.45 & 5.48 & & & & & & \\
\hline \multirow{5}{*}{ Steps (n) } & 1 & 713 & 130 & 673 & 752 & 389 & 979 & \multirow{5}{*}{3.504} & \multirow{5}{*}{0.017} & \multirow{5}{*}{0.961} & \multirow{5}{*}{1.000} & \multirow{5}{*}{$*$} & \multirow{5}{*}{$\gamma$} \\
\hline & 2 & 657 & 117 & 621 & 692 & 421 & 932 & & & & & & \\
\hline & 3 & 647 & 132 & 607 & 686 & 295 & 993 & & & & & & \\
\hline & 4 & 623 & 157 & 576 & 671 & 288 & 986 & & & & & & \\
\hline & TG & 2616 & 543 & 2452 & 2779 & 1065 & 3728 & & & & & & \\
\hline \multirow{5}{*}{ Steps/min } & 1 & 35 & 6 & 33 & 37 & 22 & 49 & \multirow{5}{*}{2.093} & & & & & \\
\hline & 2 & 34 & 7 & 32 & 36 & 21 & 47 & & & & & & \\
\hline & 3 & 33 & 7 & 31 & 35 & 13 & 44 & & 0.103 & 0.961 & 1.000 & & \\
\hline & 4 & 32 & 7 & 30 & 34 & 12 & 46 & & & & & & \\
\hline & TG & 33 & 6 & 31 & 35 & 16 & 44 & & & & & & \\
\hline & 1 & 1164 & 145 & 1120 & 1208 & 865 & 1434 & & & & & & \\
\hline & 2 & 1089 & 112 & 1055 & 1123 & 902 & 1339 & & & & & & \\
\hline Distance (m) & 3 & 1083 & 127 & 1045 & 1121 & 730 & 1309 & 4.774 & 0.003 & 0.982 & 1.000 & $* *$ & $\gamma$ \\
\hline & 4 & 1049 & 194 & 990 & 1107 & 690 & 1738 & & & & & & \\
\hline & TG & 4330 & 603 & 4149 & 4512 & 1832 & 5553 & & & & & & \\
\hline & 1 & 58 & 7 & 56 & 60 & 44 & 74 & & & & & & \\
\hline & 2 & 56 & 7 & 54 & 58 & 45 & 78 & & & & & & \\
\hline Distance/min (m/min) & 3 & 54 & 6 & 53 & 56 & 44 & 71 & 3.264 & 0.023 & 0.986 & 1.000 & $*$ & $\gamma$ \\
\hline & 4 & 54 & 7 & 51 & 56 & 42 & 68 & & & & & & \\
\hline & TG & 55 & 5 & 53 & 57 & 45 & 70 & & & & & & \\
\hline
\end{tabular}


Table 3. Cont.

\begin{tabular}{|c|c|c|c|c|c|c|c|c|c|c|c|c|c|c|}
\hline \multirow{2}{*}{\multicolumn{2}{|c|}{ Variables }} & \multirow{2}{*}{ Periods } & \multirow{2}{*}{ Mean } & \multirow{2}{*}{ SD } & \multicolumn{2}{|c|}{$95 \%$ IC } & \multirow{2}{*}{ Min } & \multirow{2}{*}{$\operatorname{Max}$} & \multirow{2}{*}{$F$} & \multirow{2}{*}{ Sig. } & \multirow{2}{*}{$f$} & \multirow{2}{*}{$\phi$} & \multirow{2}{*}{$p$} & \multirow{2}{*}{$\mathrm{DbF}$} \\
\hline & & & & & L & $\mathbf{U}$ & & & & & & & & \\
\hline \multirow{20}{*}{$\begin{array}{l}\text { Speed Zones } \\
\text { (m) }\end{array}$} & \multirow{5}{*}{$\mathrm{V}_{1}$} & 1 & 513.89 & 83.25 & 488.58 & 539.20 & 358.02 & 718.21 & \multirow{5}{*}{0.312} & \multirow{5}{*}{0.816} & \multirow{5}{*}{0.974} & \multirow{5}{*}{1.000} & & \\
\hline & & 2 & 499.80 & 67.48 & 479.29 & 520.32 & 382.38 & 672.81 & & & & & & \\
\hline & & 3 & 502.95 & 73.09 & 480.99 & 524.91 & 361.80 & 690.82 & & & & & & \\
\hline & & 4 & 498.61 & 102.78 & 467.73 & 529.49 & 262.55 & 845.39 & & & & & & \\
\hline & & TG & 2000.06 & 317.48 & 1904.68 & 2095.45 & 765.11 & 2777.68 & & & & & & \\
\hline & \multirow{6}{*}{$\mathrm{V}_{2}$} & 1 & 389.45 & 54.72 & 372.81 & 406.08 & 280.06 & 530.40 & \multirow{5}{*}{1.460} & \multirow{5}{*}{0.227} & \multirow{5}{*}{0.978} & \multirow{5}{*}{1.000} & & \\
\hline & & 2 & 370.14 & 45.50 & 356.31 & 383.98 & 277.85 & 484.52 & & & & & & \\
\hline & & 3 & 368.38 & 46.63 & 354.37 & 382.39 & 275.89 & 491.62 & & & & & & \\
\hline & & 4 & 368.67 & 73.35 & 346.64 & 390.71 & 224.66 & 641.77 & & & & & & \\
\hline & & TG & 1483.23 & 201.53 & 1422.69 & 1543.78 & 737.59 & 1901.84 & & & & & & \\
\hline & & 1 & 235.71 & 55.92 & 218.71 & 252.71 & 138.31 & 370.24 & \multirow{5}{*}{9.974} & \multirow{5}{*}{0.000} & \multirow{5}{*}{0.925} & \multirow{5}{*}{1.000} & \multirow{5}{*}{$* *$} & \multirow{5}{*}{$\alpha \beta \gamma$} \\
\hline & \multirow{4}{*}{$\mathbf{V}_{3}$} & 2 & 202.40 & 61.41 & 183.73 & 221.07 & 86.73 & 399.46 & & & & & & \\
\hline & & 3 & 194.79 & 62.52 & 176.00 & 213.57 & 52.88 & 329.70 & & & & & & \\
\hline & & 4 & 169.15 & 51.16 & 153.78 & 184.52 & 69.67 & 339.18 & & & & & & \\
\hline & & TG & 794.13 & 201.76 & 733.52 & 854.75 & 329.51 & 1399.68 & & & & & & \\
\hline & & 1 & 19.47 & 13.88 & 15.25 & 23.68 & 2.99 & 59.76 & & & & & & \\
\hline & & 2 & 13.99 & 10.93 & 10.67 & 17.31 & 0.00 & 45.15 & & & & & & \\
\hline & $\mathrm{V}_{4}$ & 3 & 14.89 & 12.02 & 11.28 & 18.50 & 0.00 & 53.39 & 6.167 & 0.001 & 0.614 & 1.000 & $* *$ & $\gamma$ \\
\hline & & 4 & 9.03 & 8.54 & 6.46 & 11.60 & 0.00 & 33.16 & & & & & & \\
\hline & & TG & 56.70 & 34.11 & 46.46 & 66.95 & 0.00 & 143.31 & & & & & & \\
\hline
\end{tabular}

Note: $\mathrm{SD}=$ Standard Deviation; $\mathrm{CI}=$ Confidence Interval; $\mathrm{L}=$ Lower; $\mathrm{U}=$ Upper; Min = Minimum; Max = Maximum; DbP = Differences between periods; Acc = Accelerations; Dec = Decelerations; $\operatorname{Vmax}=$ Maximum Speed; Vavg = Average Speed; ${ }^{* *}=p<0.01 ; *=0.05 ; \mathrm{f}=$ Effect Size; $\phi=$ Power; $\alpha=$ Differences between first and second periods; $\beta=$ Differences between first and third periods; $\gamma=$ Differences between first and fourth periods; $\varepsilon=$ Differences between second and fourth periods. 
Table 4. Descriptive and Inferential Results of the External Load Variables (Neuromuscular Variables).

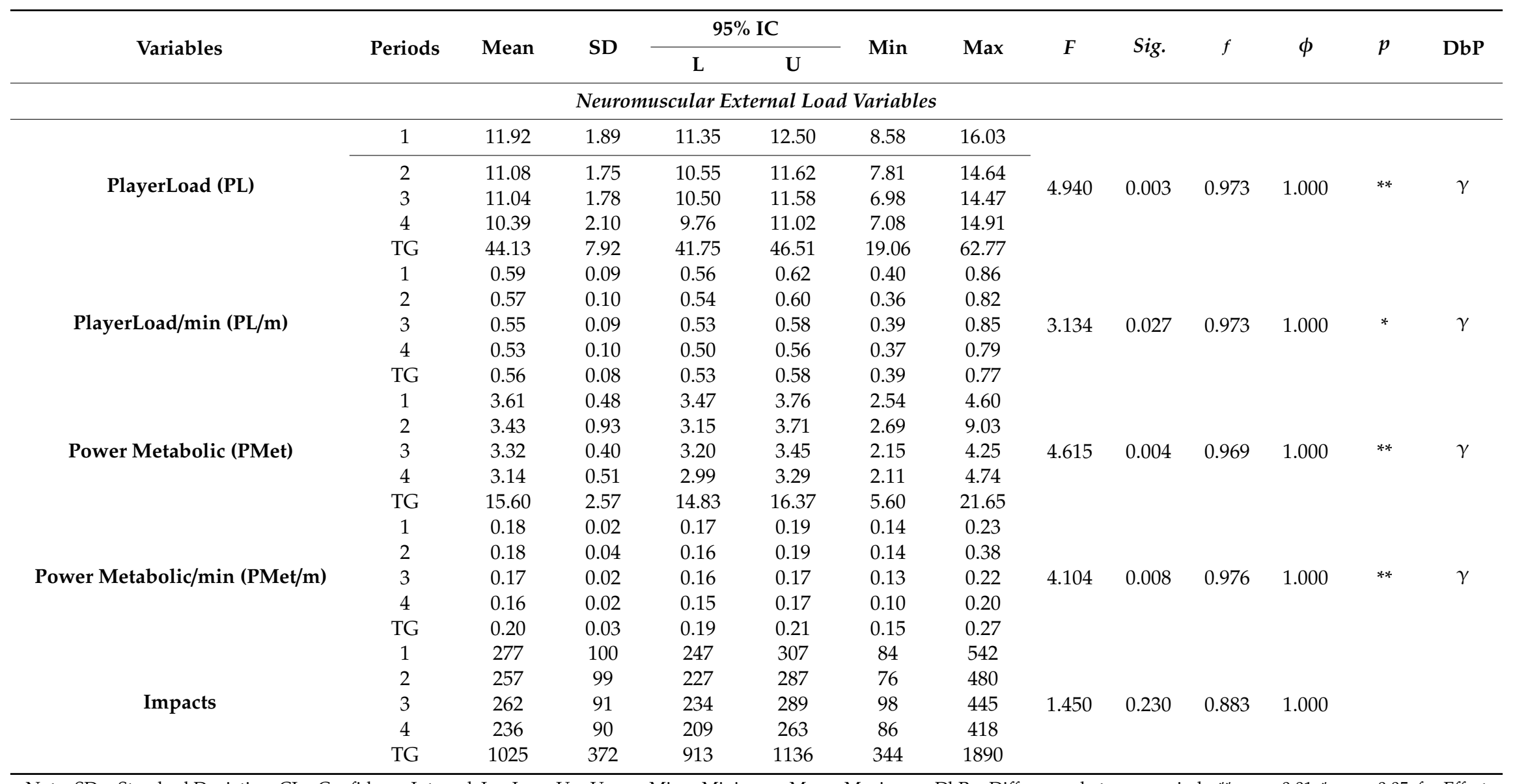

Note: $\mathrm{SD}=$ Standard Deviation; $\mathrm{CI}=$ Confidence Interval; $\mathrm{L}=\mathrm{Low} ; \mathrm{U}=$ Upper; $\mathrm{Min}=$ Minimum; Max $=$ Maximum; DbP = Differences between periods; ${ }^{* *}=p<0.01 ;{ }^{*}=p<0.05 ; \mathrm{f}=$ Effect

Size; $\phi=$ Power; $\gamma=$ Differences between first and fourth periods. 


\section{Discussion}

The purpose of this study was to identify the internal and external demands placed on basketball referees through UWB technology and in relation to the period of the game. The results highlight the need to monitor and quantify the various types of demands placed on these officials in order to establish a performance profile that will facilitate interventions with referees to benefit their performance in competition $[4,6]$. The principal findings from this study revealed a decrease in workload demands over the course of the game.

Heart rate levels have been previously examined as an indicator of internal load on referees. Previous research has found values corresponding to 60-70\% HRmax as being customary in handball [17] and basketball [9], and for values to exceed $80 \%$ in futsal [15] and in a different basketball study [11,12]. In the present study, the referees were working around $62 \%$ HRMax, which were similar values to those obtained in previous studies [9], but far below values in recent studies (>85\% HRMax) [11,12]. However, heart rate values can vary in relation to the type of officiating, the level of competition, and the gender of the players [12,23], as well as the ability level of the players. In fact, the only study in which researchers found a \%HRMax similar to this study was in a women's tournament [9], as in the present investigation. In men's basketball, the game is played at a greater tempo, owing to the greater relative physiological capacities of the players [44]. In this study, the \%HRMax was calculated in relation to the HRmax of each referee in each period of play through current and direct measurement. In other studies, HRMax was determined in a more indirect manner $[9,11]$, thus generating a less precise assessment, which makes it difficult to compare findings directly with the present data. It is recognized that elite level athletes generally make good decisions under circumstances of stress and fatigue [45], particularly in those circumstances of great challenge [46]. The referees in this study were not generally in a state of high intensity. The decision-making quality tends to decrease in circumstances of moderate intensity for many participants in sport, which makes it more probable that referees will make mistakes at moderate and low physical demand [11]. Low intensity is associated with the greatest likelihood of committing mistakes, but it should be noted that HRmax is also reflective of the gender of the players participating [12]. As such, it would be necessary to conduct studies that examine how decision-making quality in referees varies in relation to physiological stress and accumulated fatigue during games with the goal of preparing accordingly for the circumstances that will be encountered by the referees, particularly for the demands at the end of games, since each decision has a great impact on the results [25].

In relation to the external variables, it is clear that the findings from this study are consistent with previous results relative to distance covered by referees in similar research studies (around $4400 \mathrm{~m}$ per game) $[1,20,22]$, even though the instruments that were used to obtain the data were less direct, such as pedometers or VTB. The UWB technology was utilized in this study as a means of collecting data, and this methodology has greater validity than the VTB approach [31], as well as greater precision and better validity and reliability estimates than the distance and speed data that is acquired through GPS technology [29]. In terms of the running velocity of the referees in this sample, the findings are consistent with results obtained in other studies with basketball referees [1]. In this case, referees spend $\sim 80 \%$ of the game time in the walking and jogging $(0-12 \mathrm{~km} / \mathrm{h})$ speed zone, which probably has matches with low intensity, depending on the game style and the characteristics of the competition, teams, and players. Instead, football referees perform movements below $12 \mathrm{~km} / \mathrm{h}$ for $65 \%$ of the match [19]; these results are different because the distance covered in football is more than basketball. In both cases, similar time values exist in high intensity or sprint actions. Accelerations and decelerations can also be determined through changes in direction and rhythm in team sports in response to the opponent's actions relative to the field of play [47]. The acceleration and deceleration data is also of vital importance for referees given their need to match the demands placed upon the players during the game with the constant changes of direction that occur as players shift direction from one basket to the other and move side-to-side in accordance with the movement of the ball. To the best of our knowledge, this is the first study to examine acceleration and deceleration in basketball referees in a game situation. 
The results revealed a total of 1079 accelerations and 505 decelerations per game. High-intensity and low-intensity accelerations and decelerations have also been linked to markers of creatine kinase (CK) and musculoskeletal damage, given that they are actions that the body cannot readily absorb [37]. This muscular damage negatively affects muscular function over the subsequent $24 \mathrm{~h}$ and is still perceived as muscular soreness by athletes an additional $24 \mathrm{~h}$ later [48]. Consequently, monitoring this information may permit better scheduling of rest for referees, especially in condensed championship circumstances in which there are games played every day, as was the case in the present study.

The data from others variables, such as the PL, allow for an improved understanding of the demands and volume of effort experienced by the referees during the game, which allows for a better determination of referee performance outcomes. Recent studies have found that these types of variables constitute the best type of data for predicting performance in athletes [3,49], and are the indicators most strongly associated with speed, acceleration, and deceleration [50]. Unconventional movements, such as lateral or side-to-side movements and backwards running, are movements carried out at low speed, but which place high demand on athletes. These actions are quantified through the PL. Other measurement parameters for internal and external demands may underestimate the workload experienced by athletes and, as such, may not be reliable indicators to use in training, and additional accelerometry data may be needed to supplement this information [51]. The PL data is also useful because it provides information relative to the workload that athletes experience during training and competition, and is related to the risk of injury in players [37]. The use of Metabolic Power allows for the development of workload profiles in training and competition in team sports [52], and reflects the energy expenditure of referees, given the strong relationship between aerobic capacity and oxygen consumption $[39,50]$.

The findings from this study reveal that cardiovascular stress decreases over the course of the game, which is consistent with previous research [53]; the study also revealed the external demands such as distance covered, PL, and PMet. Various studies indicate that this occurrence may be due to the accumulated fatigue of the referees or due to the decrease in the pace of play of the game as players become fatigued [54]. However, the previous research was all conducted in football, where there are a limited number of substitutions permitted, and the majority of players remain on the pitch for the entire game, which contributes to greater accumulated fatigue among the players. In the sport of basketball, the players may be substituted, and then return to play, following rest periods during the game. In addition, the greatest interruptions to play occur during the final five minutes of the game [55]. Although the end of the game is associated with the greatest potential for change in the game's outcome [56], the frequent interruptions to play allow for the physical recuperation of the referees and the players during this time frame. To the contrary, the beginning of the game is associated with the time frame in which teams try to impose their style of play on the opponent with the objective of gaining an early advantage that will translate to a lead on the scoreboard [56]. Thus, it is necessary to understand the dynamics with which the games are played in order to best interpret and quantify the variables that influence the performance of referees. Furthermore, it is essential to adjust the preparation of the referees according to the specific demands that are anticipated in relation to each period of play in order to minimize the decision-making errors that may occur due to sub-optimal physical preparation practices.

\section{Conclusions}

The findings permit some conclusions relative to internal and external outcomes through use of the inertial device (WIMU $\mathrm{PRO}^{\mathrm{TM}}$ ), which enables an objective and reliable assessment of the workload demands experienced by basketball referees during competition. These findings are only determined for the sample that has participated in this study. It would be interesting to continue in this way with referees of different categories and competitions. In addition, monitoring and quantifying the workload of basketball referees is necessary to design individualized training programs for each official. 
Such training programs should be adjusted according to specific competitive characteristics to conform to these demands.

\section{Practical Applications}

It is also recommended that integrated training programs be conducted that combine physical demands with decision-making demands in the natural environment of officiating. For example, training programs can be designed where there is an intense workload at the beginning with elevated HRmax, or long training sessions in which there is considerable accumulated fatigue, but at a work demand that does not surpass $60-70 \%$ of HRmax while engaging in game-related decision-making. These different approaches to physical preparation should provide referees with the opportunity to perform at a higher level during critical moments of the game.

Author Contributions: D.G.-S: conceptualization, data collection, formal analysis, investigation, methodology, software, visualization, writing original draft; J.P.-O: data collection, software, funding acquisition, supervision, writing original draft, writing, review, and editing; J.G.-R: data collection, funding acquisition, supervision, writing original draft, writing, review, and editing; A.V.: supervision, writing, review, and editing; S.J.I.: data collection, supervision, writing original draft, writing, review, and editing;

Acknowledgments: This work has been partially subsidized by the Aid to Research Groups (GR18170) from the Government of Extremadura (Department of Economy and Infrastructure); with the contribution of the European Union through the FEDER. Thanks to the collaboration from the Referees Area of International Basketball Federation.

Conflicts of Interest: The authors report no conflicts of interest.

\section{References}

1. Allegretti, L.M.; Misuta, M.S.; Nicolletti, C.; Monezi, 1.; Bonganha, V.; Daniel, J.F.; Cavaglieri, C.R.; Borin, J.P.; Montagner, P.C. Distances covered per quarter by elite basketball referees in competition. Gazz. Med. Ita. 2015, 174, 1-2.

2. Ibáñez, S.J.; García-Rubio, J.; Gómez, M.A.; González-Espinosa, S. The impact of rule modifications on elite basketball teams' performance. J. Hum. Kinet. 2018, 64, 181-193. [CrossRef] [PubMed]

3. Schelling, X.; Torres, L. Accelerometer Load Profiles for Basketball-Specific Drills in Elite Players. J. Sports Sci. Med. 2016, 15, 585. [PubMed]

4. Vaquera, A.; Mielgo-Ayuso, J.; Calleja-González, J.; Leicht, A.S. Sex differences in cardiovascular demands of refereeing during international basketball competition. Physician Sportsmed. 2016, 44, 164-169. [CrossRef] [PubMed]

5. Myers, N.D.; Feltz, D.L.; Guillén, F.; Dithurbide, L. Development of, and initial validity evidence for, the Referee Self-Efficacy Scale: A multistudy report. J. Sport Exerc. Psychol. 2012, 34, 737-765. [CrossRef] [PubMed]

6. García-Santos, D.; Ibáñez, S.J. Diseño y validación de un instrumento de observación para la valoración de un árbitro de baloncesto (IOVAB). Sport TK—Rev. Euroam. Cienc. Dep. 2016, 5, 15-26. [CrossRef]

7. Ruiz, A.; Reina, R.; Luis, V.; Sabido, R.; Moreno, F.J. Estrategias de búsqueda visual elaboradas por árbitros de baloncesto con diferente nivel de experiencia. Un estudio de casos. [Visual search strategies utilized by referees of differing experience levels]. Cult. Cienc. Dep. 2004, 1, 32-37. [CrossRef]

8. Impellizzeri, F.M.; Marcora, S.M.; Coutts, A.J. Internal and external training load: 15 years on. Int. J. Sport Physiol. Perform. 2019, 14, 270-273. [CrossRef]

9. Leicht, A.S. Physiological demands of basketball refereeing during international competition. J. Sci. Med. Sport 2008, 11, 357-360. [CrossRef]

10. Matković, A.; Rupčić, T.; Knjaz, D. Physiological load of referees during basketball games. Kinesiology 2014, $46,258-265$.

11. Vaquera, A.; Renfree, A.; Thomas, G.; St Clair Gibson, A.; Calleja-González, J. Heart Rate Responses of Referees During the 2011 EuroBasket Championship. J. Hum. Sport Exerc. 2014, 9, 43-48. [CrossRef]

12. Vaquera, A.; Mielgo-Ayuso, J.; Calleja-Gonzalez, J.; Leicht, A.S. Cardiovascular and perceptual stress of female basketball referees during women's International matches. J. Sports Med. Phys. Fit. 2017, 57, 476-482. 
13. Reilly, T.; Gregson, W. Special populations: The referee and assistant referee. J. Sports Sci. 2006, $24,795-801$. [CrossRef] [PubMed]

14. Castillo, D.; Cámara, J.; Yanci, J. Análisis de las respuestas físicas y fisiológicas de árbitros y árbitros asistentes de fútbol durante partidos oficiales de Tercera División de España [Analysis of the physical and physiological responses of referees and referees' assistants during oficial 3rd Division matches in Spain]. RICYDE Rev. Int. Cienc. Dep. 2016, 12, 250-261.

15. Dixon, D. A pilot study of the physiological demands of futsal referees engaged in international friendly matches. Am. J. Sports Sci. Med. 2014, 2, 103-107. [CrossRef]

16. Ahmed, H.; Davison, G.; Dixon, D. Analysis of activity patterns, physiological demands and decision-making performance of elite Futsal referees during matches. Int. J. Perform. Anal. Sport 2017, 17, 737-751. [CrossRef]

17. Da Silva, J.F.; Castagna, C.; Carminatti, L.J.; Foza, V.; Guglielmo, L.G.A.; de Oliveira, F.R. Physiological demands of team-handball referees during games. J. Strength Cond. Res. 2010, 24, 1960-1962. [CrossRef]

18. García-Santos, D.; Gamonales, J.M.; León, K.; Muñoz, J. A case study: Characterization of physiological, Kinematic and neuromuscular demands of handball referee during competition. E-Balonmano: Rev. Cienc. Dep. 2017, 13, 207-216.

19. Gómez-Carmona, C.; Pino-Ortega, J. Kinematic and physiological analysis of the performance of the referee football and its relationship with decision making. J. Hum. Sport Exerc. 2016, 11, 397-414. [CrossRef]

20. Nabli, M.A.; Abdelkrim, N.B.; Castagna, C.; Jabri, I.; Batikh, T.; Chamari, K. Energy Demands and Metabolic Equivalents (METS) in U-19 Basketball Refereeing During Official Games. J. Sports Med. Doping Stud. 2017, 7, 190. [CrossRef]

21. O'Hara, J.P.; Brightmore, A.; Till, K.; Mitchell, I.; Cummings, S.; Cooke, C.B. Evaluation of movement and physiological demands of rugby league referees using global positioning systems tracking. Int. J. Sports Med. 2013, 34, 825-831. [CrossRef] [PubMed]

22. Borin, J.P.; Daniel, J.F.; Bonganha, V.; de Moraes, A.M.; Cavaglieri, C.R.; Mercadante, M.A.; da Silva, M.T.N.; Montagner, P.C. The distances covered by basketball referees in a match increase throughout the competition phases, with no change in physiological demand. Open Acess J. Sport Med. 2013, 4, 193-198.

23. Nabli, M.A.; Ben Abdelkrim, N.; Fessi, M.S.; DeLang, M.D.; Moalla, W.; Chamari, K. Sport science applied to basketball refereeing: A narrative review. Physician Sportsmed. 2019, 1-10. [CrossRef] [PubMed]

24. Larkin, P.; O’Brien, B.; Mesagno, C.; Berry, J.; Harvey, J.; Spittle, M. Assessment of decision-making performance and in-game physical exertion of Australian football umpires. J. Sports Sci. 2014, 32, 1446-1453. [CrossRef] [PubMed]

25. Paradis, K.; Larkin, P.; O'Connor, D. The effects of physical exertion on decision-making performance of Australian football umpires. J. Sports Sci. 2016, 34, 1535-1541. [CrossRef] [PubMed]

26. Malone, J.J.; Lovell, R.; Varley, M.C.; Coutts, A.J. Unpacking the black box: Applications and considerations for using GPS devices in sport. Int. J. Sports Physiol. Perform. 2017, 12, 2-18. [CrossRef] [PubMed]

27. Costa, E.C.; Vieira, C.M.; Moreira, A.; Ugrinowitsch, C.; Castagna, C.; Aoki, M.S. Monitoring external and internal loads of Brazilian soccer referees during official matches. J. Sports Sci. Med. 2013, 12, 559-564.

28. Castillo, D.; Yanci, J.; Cámara, J.; Weston, M. The influence of soccer match play on physiological and physical performance measures in soccer referees and assistant referees. J. Sports Sci. 2016, 34, 557-563. [CrossRef]

29. Bastida-Castillo, A.; Gómez-Carmona, C.; de la Cruz, E.; Pino Ortega, J. Accuracy, intra- and inter-unit reliability, and comparison between GPS and UWB-based position-tracking systems used for time-motion analyses in soccer. Eur. J. Sport Sci. 2018, 18, 450-457. [CrossRef]

30. Leser, R.; Schleindlhuber, A.; Lyons, K.; Baca, A. Accuracy of an UWB-based position tracking system used for time-motion analyses in game sports. Eur. J. Sport Sci. 2014, 14, 635-642. [CrossRef]

31. Serpiello, F.R.; Hopkins, W.G.; Barnes, S.; Tavrou, J.; Duthie, G.M.; Aughey, R.J.; Ball, K. Validity of an ultra-wideband local positioning system to measure locomotion in indoor sports. J. Sports Sci. 2017, 36, 1727-1733. [CrossRef] [PubMed]

32. Rhodes, J.; Mason, B.; Perrat, B.; Smith, M.; Goosey-Tolfrey, V. The validity and reliability of a novel indoor player tracking system for use within wheelchair court sports. J. Sports Sci. 2014, 32, 1639-1647. [CrossRef] [PubMed]

33. Ato, M.; López, J.J.; Benavente, A. A classification system for research designs in psychology. An. Psicol. 2013, 29, 1038-1059. 
34. Whaley, M.H.; Kaminsky, L.A.; Dwyer, G.B.; Getchell, L.H.; Norton, J.A. Predictors of over- and underachievement of age-predicted maximal heart rate. Med. Sci. Sports Exerc. 1992, 24, 1173-1179. [CrossRef] [PubMed]

35. Puente, C.; Abián-Vicén, J.; Areces, F.; López, R.; Del Coso, J. Physical and physiological demands of experienced male basketball players during a competitive game. J. Strength Cond. Res. 2017, 31, 956-962. [CrossRef]

36. Barret, S. The Utility of PlayerLoadTM in Soccer: An Examination of the Reliability, Validity, Determinants and the within Match Patterns. Ph.D. Thesis, University of Hull, Hull, UK, 2016.

37. Barreira, P.; Robinson, M.A.; Drust, B.; Nedergaard, N.; Raja Azidin, R.M.F.; Vanrenterghem, J. Mechanical Player Load ${ }^{\mathrm{TM}}$ using trunk-mounted accelerometry in football: Is it a reliable, task-and player-specific observation? J. Sports Sci. 2017, 35, 1674-1681. [CrossRef]

38. Cormack, S.J.; Mooney, M.G.; Morgan, W.; McGuigan, M.R. Influence of neuromuscular fatigue on accelerometer load in elite Australian football players. Int. J. Sports Physiol. Perform. 2013, 8, 373-378. [CrossRef]

39. Osgnach, C.; Poser, S.; Bernardini, R.; Rinaldo, R.; Di Prampero, P.E. Energy cost and metabolic power in elite soccer: A new match analysis approach. Med. Sci. Sports Exerc. 2010, 42, 170-178. [CrossRef]

40. Molina-Carmona, I.; Gómez-Carmona, C.D.; Bastida-Castillo, A.; Pino-Ortega, J. Validez del dispositivo inercial WIMU PRO para el registro de la frecuencia cardiaca en un test de campo. Sportk: Rev. Euroam. Cienc. Dep. 2018, 7, 81-86. [CrossRef]

41. Gómez-Carmona, C.D.; Bastida-Castillo, A.; García-Rubio, J.; Ibáñez, S.J.; Pino-Ortega, J. Static and dynamic reliability of WIMU PRO ${ }^{\mathrm{TM}}$ accelerometers according to anatomical placement. Proc. Inst. Mech. Engin. Part P J. Sports Eng. Tech. 2018, 233, 238-248. [CrossRef]

42. Field, A. Discovering Statistics Using SPSS, 3rd ed.; SAGE: London, UK, 2009.

43. Cárdenas, J.M.; Arancibia, H. Potencia estadística y cálculo del tamaño del efecto en G* Power: Complementos a las pruebas de significación estadística y su aplicación en psicología [Statistical power and effect size calculation in G Power: Complementary approaches to significance tests and their application in psychology]. Salud Soc. 2014, 5, 210-244.

44. Ziv, G.; Lidor, R. Physical attributes, physiological characteristics, on-court performances and nutritional strategies of female and male basketball players. Sports Med. 2009, 39, 547-568. [CrossRef] [PubMed]

45. Royal, K.A.; Farrow, D.; Mujika, I.; Halson, S.L.; Pyne, D.; Abernethy, B. The effects of fatigue on decision making and shooting skill performance in water polo players. J. Sports Sci. 2006, 24, 807-815. [CrossRef] [PubMed]

46. Kitsantas, A.; Zimmerman, B.J. Comparing self-regulatory processes among novice, non-expert, and expert volleyball players: A microanalytic study. J. Appl. Sport Psychol. 2002, 14, 91-105. [CrossRef]

47. Delaney, J.A.; Cummins, C.J.; Thornton, H.R.; Duthie, G.M. Importance, reliability and usefulness of acceleration measures in team sports. J. Strength Cond. Res. 2017, 32, 3485-3493. [CrossRef] [PubMed]

48. Howatson, G.; Milak, A. Exercise-induced muscle damage following a bout of sport specific repeated sprints. J. Strength Cond. Res. 2009, 23, 2419-2424. [CrossRef] [PubMed]

49. Aoki, M.S.; Ronda, L.T.; Marcelino, P.R.; Drago, G.; Carling, C.; Bradley, P.S.; Moreira, A. Monitoring Training Loads in Professional Basketball Players Engaged in a Periodized Training Program. J. Strength Cond. Res. 2017, 31, 348-358.

50. Hoppe, M.W.; Baumgart, C.; Slomka, M.; Polglaze, T.; Freiwald, J. Variability of Metabolic Power Data in Elite Soccer Players During Pre-Season Matches. J. Hum. Kinet. 2017, 58, 233-245. [CrossRef]

51. Dalen, T.; Jørgen, I.; Gertjan, E.; Havard, H.G.; Ulrik, W. Player load, acceleration, and deceleration during forty-five competitive matches of elite soccer. J. Strength Cond. Res. 2016, 30, 351-359. [CrossRef]

52. Oxendale, C.L.; Highton, J.; Twist, C. Energy expenditure, metabolic power and high speed activity during linear and multi-directional running. J. Sci. Med. Sport 2017, 20, 957-961. [CrossRef]

53. Rupčić, T.; Matković, B.R.; Knjaz, D.; Nedić, A.; Popek, S. Differences in physiological load of the referees with consideration to the period of the basketball game. SportLogia 2012, 8, 51-56. [CrossRef]

54. Weston, M.; Castagna, C.; Impellizzeri, F.M.; Rampinini, E.; Abt, G. Analysis of physical match performance in English Premier League soccer referees with particular reference to first half and player work rates. J. Sci. Med. Sport 2007, 10, 390-397. [CrossRef] [PubMed] 
55. Gómez, M.A.; Jiménez, S.; Navarro, R.; Lago-Penas, C.; Sampaio, J. Effects of coaches' timeouts on basketball teams' offensive and defensive performances according to momentary differences in score and game period. Eur. J. Sport Sci. 2011, 11, 303-308. [CrossRef]

56. García-Rubio, J.; Gómez, M.Á.; Cañadas, M.; Ibáñez, S.J. Offensive Rating-Time coordination dynamics in basketball. Complex systems theory applied to Basketball. Int. J. Perform. Anal. Sport 2015, 15, 513-526. [CrossRef]

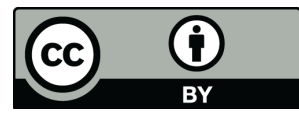

(C) 2019 by the authors. Licensee MDPI, Basel, Switzerland. This article is an open access article distributed under the terms and conditions of the Creative Commons Attribution (CC BY) license (http://creativecommons.org/licenses/by/4.0/). 